\title{
Ampicillin in the treatment of brucellosis A controlled therapeutic trial
}

\author{
D. G. McDEVITT \\ Department of Therapeutics and Pharmacology, Queen's University, Belfast
}

\begin{abstract}
McDevitt, D. G. (1970). Brit. J. industr. Med., 27, 67-71. Ampicillin in the treatment of brucellosis: A controlled therapeutic trial. A controlled therapeutic trial has been carried out with ampicillin in the treatment of brucellosis. Sixty-eight people, veterinary surgeons or their unqualified assistants, with serological evidence of brucella antibodies measured by the antihuman globulin (Coombs) test and the complement-fixation test, some of whom had symptoms consistent with a diagnosis of brucellosis, were treated in two random groups. One group was given ampicillin, $1 \mathrm{~g}$. four times a day for 28 days; the other took a placebo in identical capsules for the same period. The response to treatment was gauged by subjective improvement in symptoms four weeks after its completion and by serological improvement after four months. Fifty-four people completed the trial.

There was no evidence that ampicillin was any more effective than the placebo in treatment, either symptomatically or serologically, but $25 \%$ of the people in both treatment groups reported subjective symptomatic improvement. It is suggested, therefore, that subjective improvement alone is an inadequate criterion for assessing response to treatment in culturally unproven brucellosis, and that, because of this, current conventional therapies may require critical revaluation. Similarly, a subjective therapeutic response cannot be relied upon for diagnostic confirmation in a patient in whom the diagnosis is uncertain.
\end{abstract}

The status of the many people in occupations exposing them to bovine brucellosis with high serological titres of brucella antibody is uncertain (Annotation, 1966). They may either suffer from chronic, subclinical or latent brucellosis or have an acquired immunity with persistent antibody levels (Coghlan and Weir, 1967; Henderson, 1967). Concern has also been expressed at the large proportion of such a group which has symptoms as well as positive serological tests (Kerr, Coghlan, Payne, and Robertson, 1966a).

It would be useful to have a method of treatment that would eliminate infection in those in whom it persisted but would not harm those who were immune. As there is at present no way of distinguishing between the subclinical and immune groups, both might have to be treated.

The opportunity to investigate the treatment of an occupationally exposed group with high serological titres of brucella antibody arose during the course of a survey into the serological incidence of brucellosis in Northern Ireland (McDevitt, 1968). The resurgence of interest in brucellosis, allied to a belief in the validity of the anti-human globulin (Coombs) test and the complement-fixation test as reliable diagnostic tools, resulted in concern amongst the veterinary surgeons as to whether they might be suffering from the disease. Some had been notified of positive serology at various veterinary conferences; others had attended their medical practitioners with vague ailments and, after serological tests, been diagnosed as suffering from brucellosis. Many expressed the desire, if their serological tests were positive, to have a course of treatment, irrespective of whether they complained of symptoms or not.

It was decided, therefore, to try the effectiveness of ampicillin as a therapeutic agent in these patients. 


\section{Methods}

As part of a wider survey, sera were obtained from 116 veterinary surgeons working in practice, 75 veterinary surgeons employed by the Ministry of Agriculture in Northern Ireland, and 24 unqualified field assistants, who help the Ministry veterinary surgeons in their duties. These sera were examined by the standard agglutination test, the anti-human globulin (Coombs) test, and the complement-fixation test for brucella antibodies. The results have been reported elsewhere (McDevitt and McCaughey, 1969).

The initial results were sent to the individual veterinary surgeons: this was the condition under which some of the samples were obtained, as there was some concern that positive tests might affect livelihood. The tests were reported as 'positive' or 'negative'. A positive result was one with a Coombs titre of $1 / 80$ or greater, irrespective of complement-fixation titre, or a Coombs titre of 1/40 for Brucella abortus in the presence of a complementfixation titre of $1 / 16$ or greater (Kerr, 1967). It was pointed out that the criteria for interpretation of the tests still required further clarification, and that a 'positive' result might represent either previous infection with subsequent acquired immunity or a present infection which might be chronic, subclinical or latent.

Except for those already under the care of another physician for brucellosis, all those with tests reported as positive were invited to participate in a treatment trial which would not require time off work. Those who accepted were asked to submit a further pre-treatment blood sample. They were then randomized into two treatment groups using random numbers, with preselection for main age-groups, type of practice (private or Ministry), the presence or absence of symptoms, and high or low initial serological antibody titres.

One group received ampicillin, $1 \mathrm{~g}$. four times a day orally for 28 days; the other received a placebo, in identical capsules, for the same period. Neither the patient nor the observer knew which treatment was being given. The subjects were asked to report any side-effects of their treatment to their general practitioners, to whom details of the trial were circulated. Persistence with treatment was encouraged if side-effects were slight, but if they were severe, either the general practitioner or the veterinary surgeon could contact the observer, and were asked to do so before stopping treatment.

Four weeks after completion of the treatment course, each individual was sent a questionnaire asking for information about the treatment, any side-effects experienced and any improvement noticed. After four months, he was asked to forward a further sample of serum which was again tested for brucella antibody by the standard agglutination, the Coombs, and the complement-fixation tests. It was recognized that more regular samples would have been desirable but the difficulties of obtaining these from a group as fully occupied as the average veterinary surgeon, scattered throughout an area as large as Northern Ireland, made this impossible.

\section{Serological methods}

Serum agglutination test This was carried out by the method described by Alton and Jones (1967) at serum dilutions from $1 / 10$ to $1 / 5120$. The antigen used was an agglutinable suspension of $\mathrm{Br}$. abortus strain 99, standardized to give $50 \%$ agglutination with a $1 / 500$ dilution of International Standard Serum.

Anti-human globulin (Coombs) test The method of Wilson and Merrifield (1951), as modified by Kerr, Coghlan, Payne, and Robertson (1966b), was used. The antigen was the same as described above. Anti-human precipitating rabbit serum (Burroughs-Wellcome) was used at its optimal dilution.

Complement-fixation test This test was performed as described by Bradstreet and Taylor (1962), using a fourvolume test (unit volume $\mathbf{0 . 1} \mathrm{ml}$.) in W.H.O. plastic plates. The short fixation method only was used with 2.0 M.H.D. of complement and the optimal dilution of antigen (heat-killed $\mathrm{Br}$. abortus strain 99) as determined by a chessboard titration. In each series of tests a known control serum was included.

\section{Statistical methods}

In comparison between the various groups, the $\chi^{2}$ test was used when the numbers involved were big enough. When numbers were too small for valid application of $\chi^{2}$, the exact probability test was used. In the latter test, double tail probability is quoted.

\section{Results}

Of the 99 people to whom treatment was offered, 84 initially indicated their desire to take part in the trial. Fifteen of these failed to submit a pre-treatment blood sample and were withdrawn, as was one veterinary surgeon who reported previous penicillin sensitivity.

Thus 68 people finally participated in the trial. They comprised 45 veterinary surgeons engaged in private practice, 18 veterinary surgeons working for the Ministry of Agriculture, and five unqualified field assistants. Randomization of the two treatment groups was done before the final withdrawals and this resulted in two unequal groups: 30 people took ampicillin, $1 \mathrm{~g}$. four times a day for 28 days, and 38 took identical placebo capsules for a similar period.

Of the 68 people, $54(79 \%)$ completed their treatment, returned the post-treatment questionnaire, and submitted a final blood sample. Their details are shown in Table 1 . One other patient, who was taking the placebo, after completing the course, reported ill with symptoms ascribed to chronic brucellosis and was withdrawn for immediate treatment with tetracycline and streptomycin; four people failed to complete the treatment course three, who were on the placebo through inattention, and one from side-effects due to ampicillin. Nine people failed to send in either their post-treatment questionnaire or their post-treatment blood sample or both: five of these were taking ampicillin and four placebo. Of the 54 people completing the trial, 24 had taken ampicillin and 30 the placebo. 
TABLE 1

Characteristics OF Groups FOR AMPICILlin TRIAL

\begin{tabular}{|c|c|c|}
\hline & \multicolumn{2}{|c|}{ Group } \\
\hline & Ampicillin & Placebo \\
\hline $\begin{array}{l}\text { Total no. in group } \\
\text { No. of vets. in private practice } \\
\text { No. of vets. in Ministry employ } \\
\text { No. of assistants } \ldots \\
\text { Average age-group (years) } \ldots \\
\text { Average standard agglutination } \\
\text { titre . . . . . . } \\
\text { Range of average Coombs titre } \\
\text { Range of average complement- } \\
\text { fixation titre }\end{array}$ & $\begin{array}{c}24 \\
15 \\
6 \\
3 \\
30-40 \\
1 / 10 \\
1 / 80-1 / 160 \\
1 / 64-1 / 128\end{array}$ & $\begin{array}{c}30 \\
20 \\
9 \\
1 \\
30-40 \\
\\
1 / 10 \\
1 / 80-1 / 160 \\
1 / 64-1 / 128\end{array}$ \\
\hline
\end{tabular}

\section{Subjective improvement}

Each person was asked whether he had noticed any change in his general condition. If his answer to this question was in the affirmative he was asked to elaborate it. Six of those who took ampicillin and seven of those who took placebo said that they felt better after taking their capsules. There was thus no significant difference in subjective improvement between the two groups $\left(\chi^{2}=0.20 ;\right.$ D.F. $=1$; $0.90>P>0.80$ ). Most of the improvements related to alleviation of general tiredness, muscle tenderness and discomfort, and headaches.

\section{Serological assessment}

In the assessment of serological results, a variation of one tube up or down was allowed for laboratory technique, though failure to do so would have made little difference to the results. The three sera for each individual - initial, immediate pre-treatment, and four months post-treatment - were analysed for titre variation between the two pre-treatment sera, and between the immediate pre-treatment and the posttreatment sera. The results were recorded as 'no change', 'rise', or 'fall' and are presented in Tables 2 and 3 for both the Coombs and complement-fixation tests.

There was no significant difference between the titres of the two pre-treatment sera of the ampicillin and placebo groups measured by the Coombs test $(P=0.68)$ or the complement-fixation test $(P=$ $0 \cdot 13)$. Thus any statistically significant titre variations observed during treatment would not be expected to be due to normal fluctuation. However, there was no significant difference between the two groups in the variation of the Coombs titre $(P=0.55)$ or complement-fixation titre $(P=0.68)$ between the immediate pre-treatment and the post-treatment sera (Table 3).

Thus ampicillin, $1 \mathrm{~g}$. four times a day for 28 days, was no more effective than a placebo in producing symptomatic or subjective improvenent, or improvement in the level of the serological brucella antibodies, measured four months after treatment by the Coombs and complement-fixation tests.

\section{Side-effects of treatment}

Of the 54 patients completing their treatment, 21 complained of side-effects, as outlined in Table 4. There was a significant difference between the number of patients reporting side-effects in the two groups $(P<0 \cdot 05)$. Many of the complaints were either transient or trivial. Only one patient taking

TABLE 2

Changes in Titre before Treatment (Only differences of more than one tube between first and second specimen considered significant)

\begin{tabular}{|c|c|c|c|c|c|}
\hline \multirow{2}{*}{\multicolumn{3}{|c|}{ Treatment group }} & \multicolumn{3}{|c|}{ Titre } \\
\hline & & & \multirow{2}{*}{$\begin{array}{c}\text { Rise } \\
2 \\
2\end{array}$} & \multirow{2}{*}{$\begin{array}{c}\text { Fall } \\
\\
8 \\
7\end{array}$} & \multirow{2}{*}{$\begin{array}{c}\text { Unchanged } \\
\\
14 \\
21\end{array}$} \\
\hline $\begin{array}{cc}\text { Coombs (Abortu } \\
\text { Ampicillin }\end{array}$ & $\begin{array}{l}\cdots \\
\ldots\end{array}$ & $\begin{array}{l}\cdots \\
\cdots\end{array}$ & & & \\
\hline \multicolumn{6}{|c|}{$P=0.68$} \\
\hline $\begin{array}{c}\text { Complement fixa } \\
\text { Ampicillin }^{1} \ldots \\
\text { Placebo }^{1}\end{array}$ & $\begin{array}{l}\text { a } \\
\ldots\end{array}$ & $\begin{array}{l}\cdots \\
\ldots\end{array}$ & $\begin{array}{l}5 \\
4\end{array}$ & $\begin{array}{l}8 \\
4\end{array}$ & $\begin{array}{r}9 \\
18\end{array}$ \\
\hline
\end{tabular}

${ }^{1}$ Two sera in the ampicillin group and four in the placebo were insufficient in quantity for the test.

TABLE 3

Changes in Titre With Treatment (Only changes of more than one tube between the immediate pre-treatment and the titre four months later considered significant)

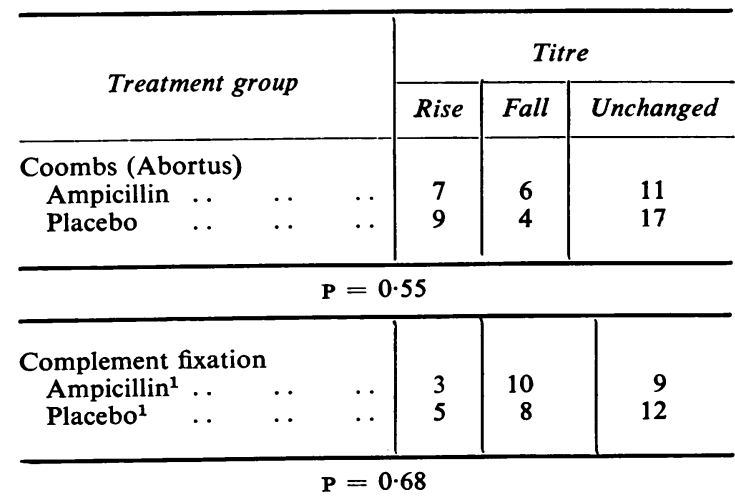

${ }^{1}$ Two sera in the ampicillin group and five in the placebo were insufficient in quantity for the test. 
ampicillin needed to stop his treatment because of side-effects - diarrhoea and pruritus ani. One general practitioner sought advice because of side-effects in a patient, who was able to complete his course of treatment. Five persons taking ampicillin failed to complete the course and this may have been due to side-effects.

\section{Discussion}

Many different therapeutic agents have been tried in the treatment of brucellosis, including sulphonamides, streptomycin, the tetracyclines, novobiocin, chloramphenicol, and nalidixic acid. The treatment of choice is generally recognized to be tetracycline (Spink, 1960; Rizzo-Naudi, Griscti-Soler, and Ganado, 1967), but it has also been recommended that streptomycin be added in severe cases (Spink, 1960) or in chronic brucellosis (British Medical Journal, 1967). Several authors do not feel that this addition augments the possibility of improvement (Farid, Miale, Omar, and Van Peenen, 1961;

TABLE 4

(a) RELATIONSHiP OF Side-EFFECTS TO TYPE OF TREATMENT

\begin{tabular}{|c|c|c|c|c|c|}
\hline \multicolumn{4}{|c|}{ Type of treatment } & $\begin{array}{l}\text { Total no. } \\
\text { in group }\end{array}$ & $\begin{array}{l}\text { No. with } \\
\text { side-effects }\end{array}$ \\
\hline $\begin{array}{l}\text { Ampicillin } \\
\text { Placebo } . .\end{array}$ & $\begin{array}{l}\cdots \\
\cdots\end{array}$ & $\ddot{n}$ & 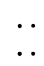 & $\begin{array}{l}24 \\
30\end{array}$ & $\begin{array}{r}15 \\
6\end{array}$ \\
\hline
\end{tabular}

(b) Side-EFFeCts EnCOUNTERed IN AMPICILlin TRIAL

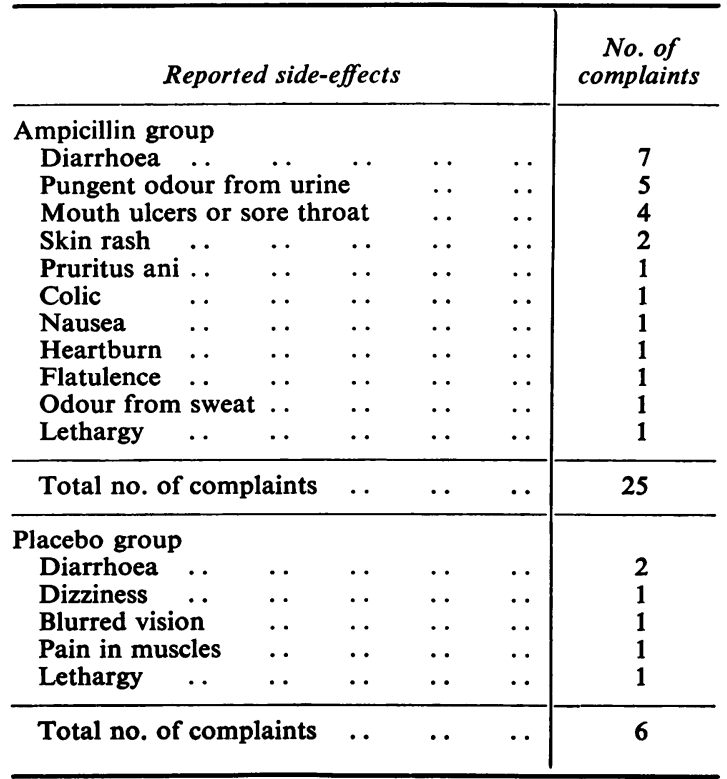

Rizzo-Naudi et al., 1967), although Richardson and Holt (1962) have shown experimentally that streptomycin acts synergistically with other antibiotics on intracellular $\mathrm{Br}$. abortus in vitro.

One of the problems of brucellosis is the intracellular localization of the brucella organisms in the tissues of the host (Spink, 1952). In these sites the bacteria are probably protected against both drugs and humoral antibodies (Magoffin and Spink, 1951; Shaffer, Kucera, and Spink, 1953), and there is experimental evidence that this protection occurs against long-term tetracycline therapy (Spink and Bradley, 1960).

Ampicillin is potentially useful in the treatment of brucellosis. Its spectrum of activity is similar to that of tetracycline (Trafford, Maclaren, Lillicrap, Barnes, Houston, and Knox, 1962); it is bactericidal (Rolinson and Stevens, 1961), whereas tetracycline is bacteriostatic. Ampicillin is active against brucellae in vitro (Agius and Mifsud, 1962; Robinson, 1966). Large doses can be taken to ensure high concentrations (Knudsen, Rolinson, and Stevens, 1961) and it has some powers of intracellular penetration (Postgraduate Medical Journal, 1964). Apart from producing skin rashes and some gastro-intestinal upset, it is safe even in high dosage (Stratford, 1964).

Unfortunately, there was no evidence from this trial that ampicillin had any beneficial effect either subjectively or serologically.

No comprehensive study of the effectiveness of ampicillin in brucellosis had been made previously. Farid, Bassily, and Omar (1964) reported two patients with Br. melitensis septicaemia who had failed to respond to ampicillin, $750 \mathrm{mg}$. four times a day. The only other reported instance of its use was by Lutton (1966) in a rather bizarre case said to be chronic brucellosis. The patient recovered but had also received streptomycin, tetracycline, sulphonamide, nystatin, and prednisone. Thus individual drug evaluation was impossible.

Since this trial began, Farid, Bassily, and Omar (1967) have reported their experience with ampicillin at a dosage level of 3-4 g./day in a further seven patients with $B r$. melitensis septicaemia. The response was disappointing. Three patients could not complete their 21-day course because of side-effects; blood cultures remained positive for many days in all patients and recourse to tetracycline had to be taken in three of the seven patients. Rizzo-Naudi and his colleagues (1967) used ampicillin in one patient with brucellosis without success.

It would seem, therefore, that ampicillin is not a useful antibiotic for brucellosis, whether acute, chronic, latent or subclinical. As far as this trial is concerned the criteria for success were very rigid and narrow. It is worth remembering that in some instances brucella antibody titres have been reported as persisting for many years (Dalrymple-Champneys, 
1929; Bartram, Bothwell, Jebb, McDiarmid, and Preston, 1963) and also that veterinary surgeons in private practice may be coming into frequent contact with infected material, so that a serological test done four months after treatment may be influenced by reinfection or exposure acquired in the intervening period.

The results of this trial indicate that great care is needed in the evaluation of the treatments for brucellosis. Chronic brucellosis is a disease with protean symptoms which may be similar to psychoneurosis with few abnormal physical signs. In the absence of culture of the organism from the patient's blood or tissues, the laboratory tests may be unhelpful both in diagnosis and in the assessment of the results of treatment. In consequence some workers have used the symptomatic improvement during treatment as evidence of the presence of disease. Other workers have used symptomatic improvement as evidence of the effectiveness of drug treatment. The finding of $25 \%$ subjective improvement in both the placebo and ampicillin-treated groups suggests that controlled assessment of treatment is especially necessary when the disease is unproven by blood culture and diagnosis depends on sensitive serological techniques. No such controlled study has previously been reported.

There would seem to be a need for further work to investigate the value of other therapies in these patients. Until this has been done a cautious and critical approach to both the diagnosis and treatment of brucellosis will be necessary.

I wish to express my gratitude to Professor O. L. Wade and Professor P. C. Elmes for their encouragement and helpful advice. My thanks are also due to D1. W. R. Kerr and Dr. W. J. McCaughey, of the Veterinary Research Laboratories, Stormont, who carried out all the laboratory procedures; to Dr. O. P. W. Robinson of Beecham Research Laboratories for the generous supply of ampicillin used in this study; to the Medical Officers of Health in Antrim, Armagh, Down, Fermanagh, Londonderry, and Tyrone for obtaining blood samples; and to the general practitioners of the veterinary surgeons for blood samples and patient management during the trial. I am also grateful to Dr. J. D. Merrett for advice about statistics.

These studies were supported by generous grants from the research funds of the Queen's University of Belfast and the Northern Ireland Hospitals Authority.

\section{References}

Agius, E., and Mifsud, J. (1962). The action of 'Penbritin' on brucella micro-organisms. Arch. Inst. Pasteur Tunis, 39, 97-101.

Alton, G. G., and Jones, L. M. (1967). Laboratory Techniques in Brucellosis. Wld. Hith Org. Monogr. Ser., N.55
Annotation. (1966). Brucellosis among veterinary surgeons. Lancet, 2 952-953.

Bartram, H. G., Bothwell, P. W., Jebb, W. H. H., McDiarmid, A., and Preston, A. E. (1963). Brucella abortus agglutinins in the sera of pregnant women and blood donors. Brit. J. prev. soc. Med., 17, 95-100.

Bradstreet, C. M. P., and Taylor, C. E. D. (1962). Technique of complement fixation test applicable to the diagnosis of virus diseases. Mth. Bull. Minist. Hlth Lab. Serv., 21, 96-104.

British Medical Journal. (1967). Any questions? Treatment of chronic brucellosis. 3, 847 .

Coghlan, J. D., and Weir, D. (1967). Antibodies in human brucellosis. Brit. med. J., 2, 269-271.

Dalrymple-Champneys, W. (1929). Undulant fever, with special reference to animal sources of infection and the possibility of its prevalence in England and Wales. Min. Hlth Rep. Publ. Hlth Med. Subj., No. 56, H.M.S.O., London.

Farid, Z., Miale, A., Omar, M. S., and Van Peenen, P. F. D. (1961). Antibiotic treatment of acute brucellosis caused by Brucella melitensis. J. trop. Med. Hyg., 64, 157-163.

—- Bassily, S., and Omar, M. S. (1964). Ampicillin in the treatment of Salmonella typhi carriers and Brucella melitensis septicaemia. Lancet, 2, 763.

,-- , and - (1967). Ampicillin 'Penbritin' in the treatment of acute Brucella melitensis septicaemia and Salmonella typhi urinary carriers. J. trop. Med. Hyg., 70, 95-98.

Henderson, R. J. (1967). Brucellosis in the dairy-farming community and allied workers of Worcestershire. Lancet, 2, 353-357.

Kerr, W. R. (1967). Personal communication. , Coghlan, J. D., Payne, D. J. H., and Robertson, L. (1966a). Chronic brucellosis in the practising veterinary surgeon. Vet. Rec., 79, 602-608.

- (1966b). The laboratory diagnosis of chronic brucellosis. Lancet, 2, 1181-1183.

Knudsen, E. T., Rolinson, G. N., and Stevens, S. (1961). Absorption and excretion of 'Penbritin'. Brit. med. J., 2, 198-200.

Lutton, A. (1966). Chronic brucellosis. Lancet, 2, 1311.

Magoffin, R. L., and Spink, W. W. (1951). The protection of intracellular brucella against streptomycin alone and in combination with other antibiotics. J. Lab. clin. Med., 37, 924-930.

McDevitt, D. G. (1968). Studies in human brucellosis. M.D. Thesis, The Queen's University of Belfast.

- and McCaughey, W. J. (1969). Brucellosis in Northern Ireland a serological survey. In press.

Postgraduate Medical Journal. (1964). Discussion. Intracellular survival of bacteria. 40 , Suppl. 94.

Richardson, M., and Holt, J. N. (1962). Synergistic action of streptomycin with other antibiotics on intracellular Brucella abortus in vitro. J. Bact., 84, 638-646.

Rizzo-Naudi, J., Griscti-Soler, N., and Ganado, W. (1967). Human brucellosis: An evaluation of antibiotics in the treatment of brucellosis. Postgrad. med. J., 43, 520-526.

Robinson, O. P. W. (1966). Personal communication.

Rolinson, G. N., and Stevens, S. (1961). Microbiological studies on a new broad-spectrum penicillin, 'Penbritin'. Brit. med. J., 2 , 191-196.

Shaffer, J. M., Kucera, C. J., and Spink, W. W. (1953). The protection of intracellular brucella against therapeutic agents and the bactericidal action of serum. J. exp. Med., 97, 77-90.

Spink, W. W. (1952). Some biologic and clinical problems related to intracellular parisitism in brucellosis. New Engl. J. Med., 247, 603-610.

- (1960). Current status of therapy of brucellosis in human beings. J. Amer. med. Ass., 172, 697-698.

- , and Bradley, G. M. (1960). Persistent parasitism in experimental brucellosis: Attempts to eliminate Brucellae with long-term tetracycline therapy. J. Lab. clin. Med., 55, 535-547.

Stratford, B. C. (1964). Some observations on the use of ampicillin in urinary tract infections. Postgrad. med. J., 40, suppl. 68-74.

Trafford, J. A. P., Maclaren, D. M., Lillicrap, D. A., Barnes, R. D. S., Houston, J. C., and Knox, R. (1962). Ampicillin: A broad spectrum penicillin. Lancet, 1, 987-990.

Wilson, M. M., and Merrifield, E. V. O. (1951). The antiglobulin (Coombs) test in brucellosis. Ibid., 2, 913-914.

Received for publication April 30, 1969. 